\title{
THE FUTURE OF PAYMENTS IN THE INTERNET OF THINGS
}

\author{
Nenad Tomić ${ }^{1}$ \\ Violeta Todorović \\ ${ }^{1}$ University of Kragujevac, \\ Faculty of Economics, \\ Kragujevac, Serbia
}

\begin{abstract}
:
Internet of things (IoT) is conceived as the highest form of integration between people and communication devices and appliances. It is a network of devices, machines, vehicles and buildings that are connected through communication networks such as the Internet, RFID and NFC, equipped with microprocessors, sensors and corresponding software for data collection, processing and timely distribution. The aim of establishing this network is the creation of an automated conditions of life and work, in which the "smart environment" allows individuals to easily navigate and quickly perform routine operations. The payments are one of the key issues in the IoT development. A large part of the emerging relations will be of business nature and they will require payment for services and products. The topic of this paper is the role and importance of electronic payments for the development of the IoT concept, and vice versa. The aim of paper is to determine the level of payments integration in the IoT processes. After defining key ideas of this concept, adoption in the corporate and consumer sector will be analyzed, as well as the payment solutions that are in the integration phase.
\end{abstract}

\section{Keywords:}

internet of things, electronic payments, M2M connections, industrial revolution 4.0 .

\section{INTRODUCTION}

Development of information and communication technologies (ICT) in the second half of 20th century has changed the way of conducting business in the great number of industries. Along with the computerization of traditional manufacturing activity, conditions for development of new service professions have been created. Computers and computer systems, which up till now have been considered as the highest form of ICT application in business and life in general, enabled collecting, processing and distribution of great amount of data, which would, practically, never be possible to do manually. Under the impact of technical progress, communication services and financial sector advanced rapidly whereas the customer electronics industry would have been completely inconceivable without these achievements. The end of 20th and the beginning of 21st century was marked by the race of producers to increase the clock speed of computer processors and graphic cards, as well as download speed of the 
internet. However, during the past few years, the attention has been moving to the networking of great number of devices and their interaction throughout gathering, processing and distribution of data.

The term Internet of Things implies the highest form of integration of devices and machines used in the business processes and everyday life. Reference [1] cites that it is the network of devices, machines, vehicles and objects which are connected via communication network such as the internet, NFC and RFID, equipped with microprocessors, sensors and suitable software that allows data collection, its processing and distribution. This way M2M type of connection is achieved, wherein both Ms could stand for machine, or one $\mathrm{M}$ for a man and the other for machine (which also could be marked as M2P, machineto-person). The aim of establishing this kind of network is the creation of automated life and work, in which "the smart environment" would enable individuals easy managing in every situation and quicker performance of routine operations. The IoT should become the base for the future information society and in long-term should serve for creation of so-called smart cities.

IoT represents the third stage of communication development via the internet. The first stage is characterized by available static content and sharp division into those who create it and those who consume it. The website content could be mostly read, watched and listened, without possibility to participate in its creation. There was one way communication. The second stage, in which we are today, is distinguished by the disappearance of clear division because the great number of sites offers interactivity. Anyone could create and consume content at the same time. Most websites contain a social component which allows participation through publication of photos, comments and videos. The most popular websites are the social networks and multidirectional communication between people occurs via computers and mobile devices. The third stage could be seen as realization of the IoT concept. According to it, the things, passive by their nature, could be transformed into intelligent, "smart" doers that could exchange information about themselves and their environment with other people and things via the internet. The communication is not only multidirectional but also goes beyond ordinary frames of devices we use.

The subject of this paper is to determine the role and importance of electronic payments for development of the concept IoT and vice versa. The aim of the paper is to confirm the achieved level of payment integration into IoT processes, and to define the guidelines for future development. The first part of the paper presents the potential of applying IoT concept in different stages of business processes. The second part analyzes the possibilities for incorporating existing payment systems and developing new ones which would allow full use of potential. The possible issues and limitations of the IoT concept are presented in the third part.

\section{APPLICATION OF THE INTERNET OF THINGS CONCEPT}

For the realization of the IoT concept, the integration of infrastructure and environment is needed [2]. The large number of devices, machines, objects and vehicles would be equipped with sensors for collecting different data. After that, data could be transferred to other devices, machines, objects and vehicles or to the individuals who are marked as authorized to access data. For instance, the vehicle owner would be able to access his vehicle as well as the data his vehicle has collected from other vehicles or from base stations with which it communicated. Also, the operator of one business process could be able to access data collected by sensors of devices and machines within his level of authorization or obtained from other connected devices and machines.

In perspective, IoT should create conditions for connecting everything into a network. With higher data speeds and greater signal coverage, in the combination with great number of devices equipped with sensors, the global network which would connect all (persons) and everything (devices) at anytime, anywhere and with any function would be created. The progressive growth of the collected data would require development of a new software for data analysis and data management (especially in corporate sector) which is, nowadays, called Big Data software. It is believed that linking these two concepts presents the future of ICT application in both business and everyday life.

Reference [4] regards that the transition of modern society to IoT standards would mark the new industry revolution, due to a great change in the manufacturing factors relationship. Consequently, the new stakeholders would appear and the new types of connections would be developed between buyers and retailers, or so to say manufacturers and service providers and suppliers. Thereby, the great number of achieved connections would be of commercial nature and it would require certain form of payment for communication. This is the opportunity not only for traditional players, such as credit card companies and mobile payment systems, but for new systems which would be better adapted to the new type of connections. 


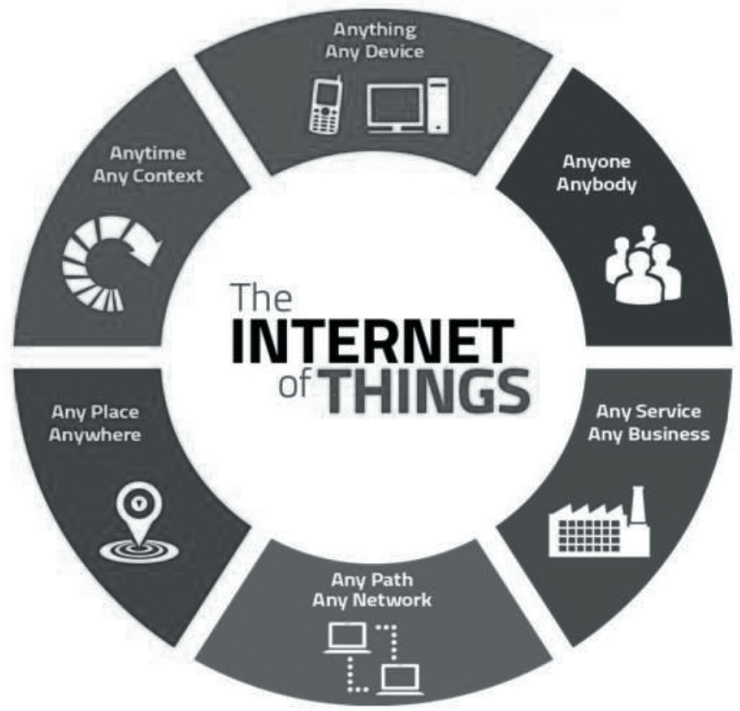

Fig. 1. Linking everything with all connections available, at anytime and anywhere

Source: [3]

There are expectations that until 2020 there would be as high as 24 billion of different devices that would meet the IoT standards in the world, which is four times more than in 2016 [5]. 5 billion of those are reserved for individual users, which represent the huge potential for increasing base of electronic payments. In the initial stage of development, key activity was to define unique standards and recommendations that laid a minimum basis which had to be met in order to achieve interoperability of future solutions. However, the infrastructure for the future has already been delivered with new models of cell phones, home devices and vehicles.

Reference [6] lists five activities with the greatest investments in the application of the IoT concept at this moment:

1. Manufacture. The manufacturing robots that perform the preset processes are not a novelty. The tracking of parts, detection of potential mistakes in the drafts or designs and optimizing process of production line management would be enabled through connection of these machines and by giving the opportunity for data exchange. With logistics automation, the operators would at any moment know the situation with the supplies in the warehouse or what raw material is lacking. With proper sensors the products tracking would be possible after them being manufactured/assembled, and thus the feedback about their condition and the way in which people reacted would be provided.
2. Transport. Smart vehicles could communicate with owner/driver or among themselves and base stations. The user gets data about vehicle condition, which could signal if components are worn out, the fuel level in the tank and quality of the fuel, or data which the vehicle gets from other vehicles. Data about traffic density, accidents or obstacles on the road, speed adjustment, etc. vehicle gets from base stations and other vehicles. Of course, the mentioned advantages are applicable not only to the road transport, but to railway, water and air transport. IoT would have great importance to freight transport.

3. Energy. In accordance with data gathered on the field, heating plants, power plants, as well as storage plants for processing and distribution of gas and oil could optimize their business. The world still dominantly uses exhaustible resources of energy, based on fossil fuel and any improvement in economizing their stocks and consumption gives a positive effects.

4. Heath care. In medical use, IoT would allow faster data exchange between different institutions and individuals involved in diagnosis and disease treatment. The implants and prostheses which could replace a body part could send feedback or could be subsequently programmed for specific function. Also, wearables provide conditions for measuring and monitoring great number of health parameters, from temperature, blood pressure and heart beat to the effect that certain treatment applied has on the organism.

5. Consumer electronics. Although the first association to mass networking is smart home, meaning that every house device informs the owner of its condition, this is just one of IoT segments. At the moment, consumer electronics do not hold the top place, although it is believed that over time, investments in this industry and smart vehicles would increase. The great number of devices can make lives of their users easier - heating or cooling which can be activated remotely, coffee machine and stove that prepare or reheat drinks and meals based on the set process, the fridge which informs the owner about the available quantity of food, the gate which recognizes the owner and the vehicle and opens and closes itself, are just some of the futuristic ideas which would be revived by this concept. 
It could be noted that at this moment, the application of IoT has greater potential in business activities rather than with individual users. However, bearing in mind diffusion of ICT in the last five decades, the high growth rate of application could be expected. In order to use a full capacity, the redesign of payment systems is obligatory.

\section{PAYMENT SYSTEMS AND INTERNET OF THINGS}

Payment systems organized on the current basis would not help in achieving the full potential of IoT. Cash payments are completely inappropriate for desired level of automation, while classic non-cash payments are very slow and expensive. Payment cards and checks are intended for transactions of significantly higher amounts than the amounts of transactions in the ecosystem of IoT would be. Reference [7] believes micropayments would be dominant method in the future, so globally connected devices usually tend to make transactions of low amounts.

Strategic changes of instrument and payment channels would be necessary for future payment system design, which in the end would cause changes of activity in the payment execution process. Payment cards terminals - POS - still dominate in terms of number of initiated transactions [8], but because of their static nature (attachment to seller's physical location) they could not be basis for payment system of IoT. Classic payment cards are not suitable to be an instrument because they require classic POS. The existing smart watches make the initial step in increasing efficiency of payment, because they could be read easily via NFC that is RFID technology. In this tap-and-go principle, the transport, shopping in markets or fast food restaurants could be paid. This, however, is not a permanent solution for IoT because transaction processing is done in the traditional way, although payments are done faster at the collection point. All citizens, that for some reason do not have payment cards, in this case remain outside of the payment system. Reference [9] thus believes that traditional banks must change business strategy if they want to survive in IoT.

Reference [10] expresses the attitude that IoT is a paradigm of information integration, in which the sensors and processors would allow machines to collect a great amount of data and distribute it. He believes that this step does not necessarily require integration of payment methods. The next evolutionary step he calls the Internet of Value (IoV) which should enable fast and efficient flow of funds. In order to achieve this, it is necessary to abandon fragmentation of existing payment systems and adopt internet organizational structure. As network of all networks, the internet enables data exchange regardless of the user's country, service provider and connection method. To enable the transition to the IoV, or to use the full potential of payment in IoT, unique payment system must become the network of all payment systems, and that network would enable the integration of national commercial banks, electronic payment systems that are developed by third party institutions or even systems of electronic money.

During designing of payment system for IoT, two key tasks would be creation of devices' digital identity or its integration through identity of the owner and achieving cost effectiveness of transactions including micropayments as well. Changes in payment infrastructure and supportive software should be regarded as the functions for resolving these two tasks.

As it is expected that the large number of devices will be able to make payments in the future, their transactions should somehow be institutionalized. One of the ideas is that every machine in one ecosystem, for instance in a smart home or a smart office, should get its own digital identity and in that way be recognized in the future transactions. The alternative is the creation of centralized system with digital identity which is based on a single device, with which all other devices are connected. Such devices are in the developmental stage, and certain solutions already exist. The example is Amazon Echo, smart sound system through which the user can communicate with the digital assistant Alexa. This assistant can wake the user up, remind him of his obligations, provide the data from connected services (time, traffic, stock market) and manage great number of house devices (from fridge to television, depending on a connected model). The system communicates with the user because it recognizes voice calling and the set of commands in English and German language [11]. Echo or Alexa are ideal digital identities which could be payment holders of devices to which they are connected.

There is another part of the problem, and that is definition of rights to access digital assistants, as well as the choice of payment methods. The access right should be separated from the right to the deeper interaction with a system (for instance, occasional guests could connect to Alexa or similar service if they ask for a quick information, but they would not be able to access settings) including installation of the parameters for automated purchase. Efficiency of the system depends on the solutions of several issues: whether they need to have their own financial parameters (payment system account and 
special payment instruments) or they would be connected via personal financial accounts of one or more users; how the authorization of payments would be confirmed, because this is not simple even in present when the electronic payments are made only by people; how one or more users would access systems settings, etc. Reference [10] believes that by no means the user name + password access system should be used, because this system is designed for statistical data and it is not even good solution for a present level of internet development.

Paying directly from the vehicle would be among key novelties of IoT. Along with the automated payment of tolls (which is now possible with using the right device) and parking, refueling would be integrated with payment so that the driver would not have to leave the vehicle. Reference [12] states that the purchases of entertainment content (music, maps) for cars is a segment which would record remarkable growth. Due to the frequency of transactions and their relatively high amount it is thought that the cars would get autonomous payment terminals, or so to say some sort of POS which would be connected to existing payment systems. In this way the issue of digital identity of every single vehicle would be resolved.

Another key task is to redesign payment so that it would become more economic. Suppose that the digital assistant buys automatically for the user songs of his favorite singer or articles of his favorite author. The amount of these purchases is low so they are considered to be micropayments. Their performance with existing payment mechanism would be inefficient due to high transaction costs. The alternative (if we exclude sale of package of service and products as undesirable) is payment in advance, wherein one digital identity would have "prepaid budget" which could be used for purchases. In case a transaction is attempted and there are no enough funds, the digital assistant would inform the user about the need for additional payment. This kind of solution has its flaws, but it allows faster implementation of the present system with few infrastructural changes.

A fundamental change, which would enable development of IoT full potential, would include the use of electronic money. Among numerous commercial forms of electronic money, a form of state electronic money would show up definitely in the near future, bearing in mind that China has announced this activity [13]. Among general public and number of users, Bitcoin is sticking out from commercial forms. However, chances to find it in mass application are very small because of high fluctuations. Its importance is mirrored in the creation of concept which is the base for the whole set of digital money systems called cryptocurrencies. It is worth mentioning two systems which could influence the IoT in the future - Ether and Ripple, because they go beyond the limits of classic electronic money we are accustomed to.

Ether is decentralized cryptocurrency which according to [14] holds the second place at the market capitulation (the number of issued coins multiplied with the market value of one coin) among cryptocurrencies. In this case, the coin presale principle (before the beginning of system's work) and the creation of new coins through mining were combined. The idea of the team that created Ether was its use in so called intelligent contracts, or so to say in the creating of automated applications which perform business processes independently. Reference [15] specifies the financing of venture capital fund named The DAO (The Distributed Autonomous Organization) as an example. It is a fund that has neither portfolio manager nor the management, but investors (also owners of the fund) make a decision on investments by voting, on which they have a right but they are not obliged to. This principle could be applied with slight modifications on payments of automated digital assistants, or individual devices.

Ripple is electronic money which is made by eponymous company. According to the website [14], Ripple holds the third place at the market capitulation among cryptocurrencies. The intrinsic value of the company actually lays in the fact that along with the creation of cryptocurrency it manages with unique payment system between banks which functions as RTGS system. The original idea of dealing with money remittance affairs was surpassed with creation of Ripple Protocol mechanism, through which any form of value could be transferred [16]. This means that not only money but securities, gold, virtual currencies, bonuses, etc. could be transferred as well [17]. Although there is institutionalized implementation of the system at the smaller banks level in North America, the system has not been tested globally yet. The basic idea is that the existing system executes micropayments and international payments inefficiently. Apart from excessive commissions, there is also a problem of great number of different electronic payment systems via which user directs the payment to the seller. Ripple Protocol offers an intermediary system (which would be a market maker) between two systems, which would be ready to execute transfer of funds from one system to another for a much smaller compensation than the previous one. Reference [18] offers detailed explanation of this process. 


\section{PROBLEMS AND LIMITATIONS OF INTERNET OF THINGS}

Unquestionable benefits for making business process and life easier are followed by certain doubts and visible issues which would arise with this concept application. Two key issues are economic effects and security.

The main economic problem is the question of benefit redistribution which would be brought by IoT. Whether all citizens would be in the situation to enjoy benefits of new medical methods, or whether all would enjoy increase of free time thanks to the concept of smart home? The answer in both of these cases is almost certainly negative. The complete networking of business processes would (in the near future) be done only by large and rich companies, thus personal advantages would (at least initially) be enjoyed only by wealthy individuals. The Fourth industrial revolution [19] would almost certainly deepen the differences between the rich and the poor, as all industrial revolutions did by now. In terms of development, it would be the continuation of the practice which [20] named "creative destruction". Under this construction he claims that every quantitative progress in capitalism is followed by devastation of old business paradigm, but that benefits achieved through progress overcome losses caused by leaving the old business practice.

In the context of economic problem, a new redistribution of workplaces is an unanswered question. Reference [21] claims that predictions show that as high as $47 \%$ of all workplaces in the USA are threatened by the complete application of IoT concept. All previous industrial revolutions brought less need for particular professions but at the same time they increased demand for the new ones. The immerse difference is that in the case of the first and the second industrial revolution those professions were mainly production occupations, while with the application of the IoT concept a large part of highly-educated staff or so called white collars would become redundant. It is related to those professions which could be automated so that the computers and computer network could execute them. This group includes accountants, insurance agents and real estate agents, etc. At the same time there are opportunities for new jobs in the field of software engineering, developing, technical support and maintenance. Reference [22] warns that the problem of inequality of terminated and newly created workplaces could rise.

Reference [23] along with the different aspects of the fourth industrial revolution conducts a comparative analysis of the automotive industry of Detroit in 1990 and the giants of Silicon Valley in 2014. Yearly incomes of these two industries are almost identical (250 billion of US dollars in total) except that the number of the employees in Silicon Valley is only $11.5 \%$ of the number of the employees in the automotive industry of Detroit (around 137.000 versus 1.2 million). The conclusion is that despite the same level of income of these two industries, the electronic industry seeks to create a lower number of very rich individuals while the automotive industry creates much higher number of low paid workplaces. Further computerization can have identical effects.

Besides the problem of benefits redistribution in this process, there is also an issue of speed at which those benefits would be achieved. Reference [24] says that surveyed managers specified the level of necessary investments as the key obstacle in the future implementation of IoT in business processes. To this, we should add the fact that partial innovation of one function of business process most often does not have a sense because the full effects are noted only by automation of the entire process. Financing the entire innovation is very expensive and it has to be followed by a reduction of the existing costs or an increase of the incomes.

Similar problem occurs with individual users. As much as, for instance, interactive refrigerator which shares information about amount and conditions of groceries would be useful, users would not buy the new one until their old refrigerator is not broken. Situation is even more drastic with the cars because they are much more expensive. It can take decades for networked cars to become a majority on the roads, and until then there would not been possible to achieve full advantages of ,smart traffic” with minimal involvement of the human factor.

The second great problem of IoT would definitely be security. The potential usurpation of security in the case of IoT is far greater than in the present conditions of the internet communication. Although the privacy is usually mentioned as a specific problem, which is not necessarily connected with safety, it seems that the great possibilities of IoT would contribute to unbreakable interweaving of these problems. The individual users could be confronted not only with the loss of privacy in the terms of stealing personal and financial data but with a complete tracking of life habits and practice, even with the impossibility to perform a routine operations. State secret service or criminal groups could misuse the entire smart home of the user or endanger his life if the target of hacking attack is user's vehicle. Usurpation of financial data could initiate the great financial losses due to unauthorized purchases. The possible losses in the case of attack on the business institution's smart systems could have even more devastating consequences. The industrial espionage in the 
case of IoT would contribute to the loss of practically all data about a company's business, from the procurement to product placement.

Infiltration of computer viruses could paralyze the entire business process, and an attack on financial institution would be especially devastating. Therefore, antivirus software and other security systems could be expected to have the greatest importance in functioning of IoT. Unless valid regulation is applied, IoT would make the life and business really dangerous, instead of making them simpler. If one bears in mind that current use of the internet usually leaves legal dilemmas, the challenges of complex and detailed legal regulation become clear.

The final question of security is the fear that IoT would change the life as we know it today. As the Archbishop of Canterbury said on the world forum in Davos, the technical changes would not only be the question of money, but also the concept of the man as a being. Reference [25] thinks that with the creation of smart watches and other wearables has begun the process of turning people into cyborgs. Although all body parts are still biological, people obtain senses that naturally they cannot possess. The next step could be the installation of smart body parts through prosthesis or chips, which would help people to get physical characteristics not previously owned. Progress possibilities in those cases could be on the border of imagination.

\section{CONCLUSION}

At the first sight, great possibilities for integration of people with objects and devices in the environment are clear. In the combination with high speed data transfer and better coverage of wireless internet signal, Io $T$ creates conditions for the biggest changes in lifestyle and work until now. Greater automation of life and work gives more opportunities for progress, but also creates the risk of large losses. Not only that workplaces of many people are endangered, but it also raises the question what would humanity look like if integration of people and devices gets out of control.

If we hold to the positive effects of IoT, the great progress even without payment systems integration is possible. This primarily refers to tracking of parts, semifinished products and products during manufacture, tracking of product condition and distribution, obtaining data from a field which is important for agriculture, traffic, construction, etc. In order to include individual users in the entire process, the very act of payment is not necessary, because the information distribution itself would have the great importance. Nevertheless, including the purchase process is something that all manufacturers would seek due to the possibilities for additional earning.

Mentioned systems of electronic money seem more advanced in comparison to the previous ones. Both systems are ahead of current understanding of money, so it could be expected that in the present form or with smaller modifications they could be applied in specific IoT solutions. Traditional financial institution could not be expected to give up easily the fight for the new market. The good example is Visa which for a long time announces its payment alternative Visa Ready program that would enable payment in tokens for home devices [26]. Experiences showed us that in the very start there would not be unique solution, so the new system would coexist with the existing one. In the far future the concept of state electronic money would be a generally acceptable solution for final access to IoV.

\section{REFERENCES}

[1] Global Standard Initiative for Internet of Things (2016) Harnessing the Internet of Things for global development, International Telecomunication Union, Geneva, Switzerland

[2] Russo, G., Marsigalia, B., Evangelista, F., Pamlaccio, M., Maggioni, M. (2015) Exploring regulation and scope of Internet of Things companies: a first literature analysis, Journal of innovation and enterprenuership, 4(11)

[3] http://blogs.economictimes.indiatimes.com/etcommentary/b2b-not-b2c-will-lead-internet-ofthings-adoption/ (access date: March $3^{\text {rd }}$ 2017)

[4] Greenough, J., Camhi, J. (2016) Here's why some are calling the Internet of Things the next Industrial Revolution, BussinesInsider, Febrary $10^{\text {th }}$

[5] Bakker, E. (2016) The connected device payments report: Market opportunities, top stakeholders, and new use cases for the next frontier in payments, BusinessInsider, July $14^{\text {th }}$

[6] DeNisco, A. (2017) The five industries leading the IoT revolution, ZDNet, Febrary $1^{\text {st }}$

[7] Skinner, C. (2016) Payments hold the key to the Internet of Things, The Banker, June $1^{\text {st }}$

[8] Вуксановић, Е. (2009) Електронски системи плаћаға, Економски факултет Универзитета у Крагујевцу

[9] Marous, J. (2017) Should banking build an Internet of Things strategy, The Financial Brand, January $16^{\text {th }}$

[10] Cheng, J. (2015) Towards the Internet of Value: The Internet of Things and the Future of Payment Systems, Ripple 
[11] Ranger, S. (2016) Amazon Echo review: Alexa is the first digital assistant that is actually helpful, ZDNet, October $21^{\text {st }}$

[12] Rabinovich, B. (2016) The Internet of Things and the future of payments, PaymentEye, June $23^{\text {rd }}$

[13] Zhao, Y. (2017) China Is Developing its Own Digital Currency, Bloomberg, Febrary $23^{\text {rd }}$

[14] coinmarketcap.com (access date: March $8^{\text {th }}$ 2017)

[15] Waters, R. (2016) Automated company raises equivalent of $\$ 120 \mathrm{M}$ in digital currency, CNBS, May $17^{\text {th }}$

[16] Scully, M. (2014) Alternative Money Mover Ripple Labs Enters U.S. Banking System, American Banker, September $24^{\text {th }}$

[17] Perry, J.D. (2014) The Future for Global Value Transfers, Fox Business, December $5^{\text {th }}$

[18] Thomas, S. Schwartz, E. (2015) A protocol for interledger payments, online available https://interledger.org/interledger.pdf
[19] Marr, B. (2016) Why everyone must get ready for the 4th industrial revolution, Forbes, April $5^{\text {th }}$

[20] Schumpeter, J. (1942) Capitalism, Socialism and Democracy,Harper\&Brothers, New York

[21] Elliot, L. (2016) Fourth Industrial Revolution brings promise and peril for humanity, The Guardian, January $24^{\text {th }}$

[22] Mendonca, J. (2016) IoT will cut and create jobs in different sectors: Find out if yours is at risk, Economic Times, August $19^{\text {th }}$

[23] Schwab, K. (2016) The fourth industrial revolution, World economic forum

[24] Condon, S. (2017) IoT progress has been slow down but optimism remains, ZDNet, Febrary $22^{\text {nd }}$

[25] Bisson, S. (2015) I'm a cyborg now - and so are you, ZDNet, October $21^{\text {st }}$

[26] https://usa.visa.com/visa-everywhere/innovation/ visa-brings-secure-payments-to-internet-of-things. html (access date: March $2^{\text {nd }} 2017$ ) 